\title{
Addressing spiritual well-being as a means of improving quality of life in Parkinson disease
}

\author{
Molly M. Kilpatrick ${ }^{1}$, Maisha T. Robinson ${ }^{1,2}$ \\ ${ }^{1}$ Department of Family Medicine, ${ }^{2}$ Department of Neurology, Mayo Clinic, Jacksonville, FL, USA \\ Correspondence to: Maisha T. Robinson, MD, MS. Department of Family Medicine and Neurology, Mayo Clinic, Jacksonville, FL, USA. Email: \\ Robinson.Maisha@mayo.edu. \\ Provenance and Peer Review: This article was commissioned by the Editorial Office, Annals of Palliative Medicine. The article did not undergo external \\ peer review. \\ Comment on: Prizer LP, Kluger BM, Sillau S, et al. Correlates of spiritual wellbeing in persons living with Parkinson disease. Ann Palliat Med \\ 2020;9:S16-23.
}

Submitted Nov 16, 2019. Accepted for publication Nov 30, 2019.

doi: 10.21037/apm.2019.11.30

View this article at: http://dx.doi.org/10.21037/apm.2019.11.30

There is a growing acceptance of the role of palliative care for patients with neurological diseases, given the often progressive, debilitating, and terminal nature of the conditions (1). A specific body of literature has emerged that focuses on the needs of patients with Parkinson disease and their caregivers and it highlights the significant symptom burden in this patient population (2-5). Spiritual needs are common in patients with serious and advanced medical conditions and patients desire that the health care team participates in addressing their spiritual well-being $(3,6)$. The interdisciplinary, team-based approach to care that is provided by a palliative medicine team is an ideal model for patient- and family-centered care aimed at assessing and alleviating physical, psychosocial, and spiritual suffering (2).

In this issue of Annals of Palliative Medicine, Prizer et al. (7) aimed to elucidate the association between spirituality and Parkinson disease and to explore how spiritual counseling could be optimized in the management plan for affected patients. The authors intended to establish a correlation between spirituality and Parkinson disease predictors including quality of life (QOL) and to determine whether factors such as mood, caregiver engagement, disease status, and caregiver spirituality were associated with spiritual distress in Parkinson disease patients.

Higher spiritual FACIT-Sp scores were associated with older age, presence of a caregiver, and support group involvement. The study also demonstrates an association between higher spirituality scores and higher QOL scores, lower anxiety/depression ratings [Hospital
Anxiety and Depression Scale (HADS)], fewer nonmotor and palliative symptoms [Unified Parkinson's Disease Rating Scale (UPDRS) and Edmonton Symptom Assessment System Revised: Parkinson Disease (ESASrPD)], and less prolonged grief (PG 12). They encourage spiritual assessments, access to spiritual counselors and the interdisciplinary palliative team approach to optimize care for Parkinson disease patients. The authors conclude that spirituality may mitigate some of the physical and nonmotor symptoms and may improve QOL for those with Parkinson disease, which is supported by the literature on spirituality in adults with neurologic diseases (8).

Several limitations of this study warrant further discussion. First, the study was a cross-sectional design and the authors appropriately mentioned that causation can not be inferred from the associations. Second, more clarity is needed about the study population. We are uncertain if all of the participants actually carried the diagnosis of Parkinson disease. The study participants were from a larger randomized controlled trial (9). Patients were eligible for enrollment in that trial if they met criteria for Parkinson disease and Parkinson-plus syndromes including progressive supranuclear palsy, corticobasal degeneration, multiple systems atrophy, or Lewy body dementia (9). If the study participants' diagnoses included both Parkinson disease and atypical parkinsonian disorders, then the generalizability of the study results in patients with Parkinson disease specifically would be limited.

Third, it is challenging to assess QOL outcomes given 
that multiple QOL assessment tools were used including the Parkinson's Disease Questionnaire 39 (PDQ-39), the McGill Quality of Life Questionnaire (McGill QOL), the Patient-Reported Outcomes Measurement Information System (PROMIS-29) and the Quality of Life in Alzheimer's Disease (QOL-AD). It is unclear if each patient received all of the QOL screening tools or if variability existed in the tools used with each of the participants.

Fourth, the authors acknowledge that one of their aims regarding the impact of spiritual distress could not be assessed given that none of the participants met FACITSp criteria for spiritual distress. We identified several factors which may be contributing to the overall results and limiting study outcomes.

Participants in the study by Prizer et al. (7) were excluded if immediate or existing palliative care or hospice needs were identified or if comorbid conditions which might require palliative services were present. All participants were English speaking with an average age of 70 years old. The majority of study participants were well-educated, financially stable, married, Caucasian males with over $90 \%$ having caregivers who lived in the same household. In addition, the average palliative performance scale score was 64.6 which correlates to reduced ambulation and need for only occasional assistance with self-care.

Given the relative homogeneity of the study population and the lower acuity patients from a palliative standpoint, it is possible that the authors unintentionally excluded the groups at risk for the highest symptom and disease burden, and spiritual distress. In other words, could the minimal spiritual distress in the study participants be associated with the demographic make-up, relatively high functional status, lower palliative care needs, and presence of more social support as opposed to spirituality or spiritual interventions?

Although the study addresses an important gap in the current literature, further investigation into this topic is necessary.

The study briefly discussed that the FACIT-Sp may be a better spirituality screening tool than the Royal Free Interview (RFI) used in prior Parkinson disease research. Spiritual screening tools may be an interesting area for further comparative research in the future. Additionally, the author's hypothesis regarding meaning-making and peacefocused spiritual support in minimizing prolonged grief and improving coping could be explored.

We feel that the highest impact next step would be to identify which patients with Parkinson disease are most at risk for spiritual distress using a diverse patient population.
Spiritual distress may be higher in populations who have advanced disease, significant functional impairment, and limited financial and caregiving support. Patients who have early onset Parkinson disease or who are from racial/ethnic minority backgrounds may also have different spiritual needs than the studied population. The following step would involve honing in on patients with the highest levels of spiritual distress to identify what spiritual screenings and interventions could improve suffering in that population. As the authors of this study suggest, there are opportunities to fill both knowledge and practice gaps.

In this study, Prizer et al. (7) focused on patient-related outcome measures. Religiosity and spiritual well-being in patients with serious illness can have a larger impact on the health system in terms of health care utilization, costs of care, and care at the end of life $(10,11)$. A specific focus on addressing spiritual needs may influence hospice enrollment and the intensity of life-prolonging medical care at the end of life (12). Future research could measure the downstream effects of improving spiritual well-being as a component of the comprehensive care plan in patients with neurologic disease.

Despite the above-mentioned limitations, we are in agreement with the authors of this study (7) that spiritual assessments and interventions could provide an opportunity for improved symptom management and QOL in patients with Parkinson disease. We also support the authors' recommendation for an interdisciplinary palliative care approach that involves chaplain support to address biopsychosocial and spiritual suffering, and caregiver support for those living with serious illness.

\section{Acknowledgments}

Funding: None.

\section{Footnote}

Conflicts of Interest: The authors have no conflicts of interest to declare.

Ethical Statement: The authors are accountable for all aspects of the work in ensuring that questions related to the accuracy or integrity of any part of the work are appropriately investigated and resolved.

Open Access Statement: This is an Open Access article distributed in accordance with the Creative Commons 
Attribution-NonCommercial-NoDerivs 4.0 International License (CC BY-NC-ND 4.0), which permits the noncommercial replication and distribution of the article with the strict proviso that no changes or edits are made and the original work is properly cited (including links to both the formal publication through the relevant DOI and the license). See: https://creativecommons.org/licenses/by-nc-nd/4.0/.

\section{References}

1. Robinson MT, Holloway RG. Palliative care in neurology. Mayo Clin Proc 2017;92:1592-601.

2. Boersma I, Miyasaki J, Kutner J, et al. Palliative care and neurology: time for a paradigm shift. Neurology 2014;83:561-7.

3. Boersma I, Jones J, Carter J, et al. Parkinson disease patients' perspectives on palliative care needs: what are they telling us? Neurol Clin Pract 2016;6:209-19.

4. Richfield EW, Jones EJ, Alty JE. Palliative care for Parkinson's disease: a summary of the evidence and future directions. Palliat Med 2013;27:805-10.

5. Kluger BM, Shattuck J, Berk J, et al. Defining palliative care needs in Parkinson's disease. Mov Disord Clin Pract 2018;6:125-31.

6. Mathew-Geevarughese SE, Corzo O, Figuracion E.

Cite this article as: Kilpatrick MM, Robinson MT. Addressing spiritual well-being as a means of improving quality of life in Parkinson disease. Ann Palliat Med 2020;9(2):133-135. doi: 10.21037/apm.2019.11.30
Cultural, religious, and spiritual issues in palliative care. Prim Care 2019;46:399-413.

7. Prizer LP, Kluger BM, Sillau S, et al. Correlates of spiritual wellbeing in persons living with Parkinson disease. Ann Palliat Med 2020;9:S16-23.

8. Wade JB, Hayes RB, Wade JH, et al. Associations between religiosity, spirituality, and happiness among adults living with neurological illness. Geriatrics (Basel) 2018. doi: 10.3390/geriatrics3030035.

9. Kluger BM, Katz M, Galifianakis N, et al. Does outpatient palliative care improve patient-centered outcomes in Parkinson's disease: rationale, design, and implementation of a pragmatic comparative effectiveness trial. Contemp Clin Trials 2019;79:28-36.

10. Balboni TA, Balboni M, Enzinger AC, et al. Provision of spiritual support to patients with advanced cancer by religious communities and associations with medical care at the end of life. JAMA Intern Med 2013;173:1109-17.

11. Balboni T, Balboni M, Paulk ME, et al. Support of cancer patients' spiritual needs and associations with medical care costs at the end of life. Cancer 2011;117:5383-91.

12. Balboni TA, Paulk ME, Balboni MJ, et al. Provision of spiritual care to patients with advanced cancer: associations with medical care and quality of life near death. J Clin Oncol 2010;28:445-52. 